\title{
Response of Rice and Maize Yield to Inherent Soil Productivity of Paddies and Fertilization in Chongqing China
}

\author{
Tao Liang ${ }^{1,2,4}$, Xiaojun Shi ${ }^{1,2, *}$, Yan Chen $^{3}$ and Yidan $\mathrm{Xu}^{4}$ \\ ${ }^{1}$ College of Resources and Environment, Southwest University, Chongqing, China, 400716 \\ ${ }^{2}$ The National Monitoring Base for Purple Soil Fertility and Fertilizer Efficiency, Southwest University, \\ Chongqing, China, 400716 \\ ${ }^{3}$ Beibei Administrative office, Chongqing, China, 400700 \\ ${ }^{4}$ Beibei District Agricultural Committee, Chongqing, China, 400700 \\ *swuliangtao@163.com
}

Keywords: Paddy field, dry farm, basic soil fertility, output, fertilization, Chongqing

\begin{abstract}
Through research on basic soil fertility, nutrient supply capacity and the effect of fertilization on Chongqing paddy fields and dry farms, we evaluated the impact of basic soil fertility and fertilization on the output of rice, clarifying the relationship between basic soil fertility and the utilization efficiency of nutritional absorptions of Nitrogen, Phosphorus and Potassium. Our goal was to provide a scientific reference on fertilizer for the enhancement of soil fertility and a reasonably high output of crops at low cost. This paper determines grain and straw output and the nutrient absorption of rice and maize according to the selection of five treatments: CK, PK, NK, NP and NPK5. Data were collected from 703 rice plots and maize pilots in Chongqing under the stated project of soil testing and formulated fertilization during 2006-2010. We analyzed the current condition of basic soil fertility, nutrient supply capacity and effect of fertilization, as well as the interrelation of paddy fields and dry farms in Chongqing, and estimated the fertilization effect, the output stability and sustainability across different basic soil fertilities on the basis of rice production. The basic soil fertility outputs of Chongqing paddy fields and dry farms are 6.0 and $4.0 \mathrm{t} \cdot \mathrm{hm} 2$, respectively, with sharp differences among regions. The Western Chongqing produces the highest quantity, followed by the Central Chongqing, the Southeastern and finally the Northeast with the lowest quantity. Statistical results from the experiment revealed a significant positive correlation between farmland fertilization output and basic soil fertility. Hence, basic soil fertility plays a vital role in nutrient supply capacity, yield increase from fertilizer, and the sustainability and stability of output, whether in paddy fields or dry farms. The supply capacities of Nitrogen, Phosphorus and Potassium in Chongqing paddy fields are 101, 57 and $165 \mathrm{~kg} / \mathrm{hm} 2$, respectively, with the decrease of Nitrogen, Phosphorus and Potassium under yield increase of fertilizer by 102 、 47 and $101 \mathrm{~kg} / \mathrm{hm}-2$, yield increase of fertilizers- Nitrogen, Phosphorus and Potassium keep decreased successively, which are $30.7 \%, 19.2 \%, 12.1 \%$, respectively. Nitrogen remains the most important nutrient for enhancing the output of crops. The soil fertility of paddy fields and dry farms rises to high-grade soil fertility from the middle-grade with increases in the sustainability and stability of output. In the context of low-grade soil fertility, the farmland maintains sustainability and stability in the level of low output.
\end{abstract}

\section{Introduction}

In recent years, the soil fertility of farmland in China has changed greatly. The lower to medium yield soil accounts for two-thirds of total cultivated areas, and the acidified soil was more than 26.7 million hm2 in the cultivated soil. Moreover, the organic matters in 55\% farmland had an increasing trend, which decreases in 30\% farmland soil[1]. The studies by Tang and others have shown that the contribution of soil productivity to yield of wheat, maize and rice in China were $43.06 \%, 51.06 \%$ and $61.93 \%$ [2]. The contribution rate of chemical fertilizer to grain yield was a nationwide average of $40.8 \%$ [3]. The efficiency of nitrogenous fertilizer in chemical fertilizers was greater than that of 
phosphatic fertilizer, while the phosphatic fertilizer was more efficient than potassic fertilizer. The continuous and systematic application of chemical fertilizers had a positive impact on soil fertility [4].

The inherent soil productivity was the productive capacity of farmland, which was included the elements of characteristics of soil itself, natural conditions and infrastructure, etc [5]. Studies have shown that wheat yield remains stable with conditions of high fertility soil, even with no-fertilizer for 50 years [6]. Soil productivity was the capacity to produce the harvested products of plant, which were determined by soil fertility, environmental conditions and human factors. Soil productivity mainly depends on field management, effect of water and fertilizer and basic soil productivity [7]. The level of soil productivity of farmland depends mainly on the dynamic balance between consumption and compensation of soil nutrients. The promotion and cultivation of low-level soil productivity also was the improvement of farmland of lower to medium yield [8].

How do we adapt to the trend of agricultural development, which was to obtain higher yield through lower environmental costs, under the current state of gaining high yield by high input and high cost in China. This research mainly aims at the characteristics of cultivated land in Chongqing, with the purposes of revealing the response of the basic soil productivity and yield to the fertilization in Chongqing, analyzing the relation of evaluations between basic soil productivity and soil productivity, and to provide a scientific basis for the sustainable utilization of cultivated land in Chongqing.

\section{Materials and methods}

Research area overview. Profile of topography, climate and soil in research area .Chongqing city is located in eastern part of Sichuan Basin, lying in terrain of sloped downwards from north-south to valley of Yangtze River, with main landform of hills and mountains, 76\% of which are mountains, so the city is known as "mountain city". Chongqing covers a total area of 82,000 square kilometers, with jurisdictions over 38 districts and counties(autonomous counties), a population of 33.71 million, subtropical monsoon humid climate, the annual average temperature at 16 18 degrees, and annual rainfall of 1000 1450 millimeters. The main crops in Chongqing are four major crops of rice, maize, wheat and sweet potato, with the majority of rice and maize.

Research area and test distribution. The distribution area of geographical position in Chongqing (CQ) is large, different from planting habits and ecological characteristics, which is divided into four regions according to the climate, topography, ecological conditions, soil and cultivation methods, that were WY region of Chongqing(WY), middle region of Chongqing(MY), southeast region of Chongqing(SE) and northeast region of Chongqing (NE) (Figure 1).

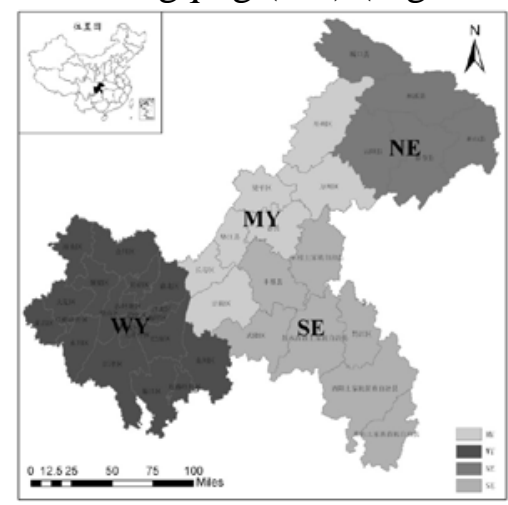

Figure 1 Distribution of different ecological regions

Grain production overview in research area. In 2014, the grain production in Chongqing was stable, without large-scale disaster, with stability of yield, and the annual sown area of grain was $6.90 \cdot 105 \mathrm{hm} 2$. Comprehensive yield per unit area of grain was $7.30 \mathrm{~kg} \cdot \mathrm{hm}-2$. In 2014, the total crop yield reached 11.45 million tons and annual grain yield was 7.97 million tons, with rice yield of 5.03 million tons accounting for $44 \%$ of total crop yield, maize yield of 2.56 million tons for $22 \%$ and 
wheat yield of 0.27 million tons for $2 \%$. Two crops of rice and maize accounted for two-third of the grain output of the CQ, and its sown area, total output and per unit yield were shown in table 1 .

Table 1 The production state of rice and maize in different regions of Chongqing

\begin{tabular}{lllllll}
\hline & Rice & & & Maize & \\
\cline { 2 - 7 } Region & Planting area & Total output & Per unit area yield & Planting area & Total output & Per unit area yield \\
& $(103 \mathrm{hm} 2)$ & $(104 \mathrm{t})$ & $(\mathrm{kg} \cdot \mathrm{hm}-2)$ & $(103 \mathrm{hm} 2)$ & $(104 \mathrm{t})$ & $(\mathrm{kg} \cdot \mathrm{hm}-2)$ \\
\hline WY & 339.2 & 266.6 & 7859.3 & 148.6 & 88.1 & 5925.3 \\
MY & 205.6 & 146.5 & 7123.8 & 115.0 & 65.7 & 5712.2 \\
SE & 99.7 & 64.2 & 6442.7 & 114.1 & 59.2 & 5188.4 \\
NE & 41.3 & 25.9 & 6266.6 & 90.1 & 43.1 & 4778.0 \\
CQ & 689.7 & 503.2 & 7296.1 & 467.9 & 256.0 & 5470.6 \\
\hline
\end{tabular}

Experimental design

Table 2 The distribution of “3414”"test plot of rice and maize in Chongqing

\begin{tabular}{llllll}
\hline Crop & WY & Middle & SE & NE & CQ \\
\hline Rice & 229 & 118 & 60 & 26 & 433 \\
Maize & 135 & 42 & 50 & 43 & 270 \\
Total & 364 & 162 & 110 & 69 & 705 \\
\hline
\end{tabular}

The research used 703 trials of rice and maize, which were conducted for a national project of fertilizer recommendation based on soil testing in Chongqing from 2006 to 2010, and included 433 trials of rice and 270 trials of maize. The representative plots of farmers were selected as experimental field, and each trial was conducted only for one harvest in the same plot where was normally managed by farmers before the experiment. Five treatments were selected for each trial: no-fertilizer (CK), single application of phosphatic and potassic fertilizer (PK), single nitrogenous and potassic fertilizer (NK), single nitrogenous and phosphatic fertilizer (NP), and application of nitrogenous, phosphatic and potassic fertilizer (NPK). The application amount of nitrogenous, phosphatic and potassic fertilizer was determined by the Chongqing Agricultural Technology Extension Station according to the specific conditions of each region, which were shown in table 3.

Table 3 The physical-chemical properties of rice and maize “3414”testing soils in Chongqing

\begin{tabular}{|c|c|c|c|c|c|c|c|c|c|}
\hline Region & Crop & Organic matter(g•kg-1) & $\mathrm{pH}$ & $\begin{array}{l}\text { Total } \\
(\mathrm{g} \cdot \mathrm{kg}-1)\end{array}$ & $\begin{array}{l}\text { Total } \\
\text { P (g.kg-1) }\end{array}$ & Total K (g-kg-1) & Available N (mg·kg-1) & Available P (mg $\cdot \mathrm{kg}-1$ ) & Available K (mg $\cdot \mathrm{kg}-1)$ \\
\hline \multirow{2}{*}{ WY } & Rice & $26.2 \pm 10.4$ & $5.7 \pm 1.0$ & $1.5 \pm 0.5$ & $0.4 \pm 0.3$ & $11.0 \pm 8.0$ & $111 \pm 51$ & $12.4 \pm 6.6$ & $121 \pm 65$ \\
\hline & Maize & $18.5 \pm 7.8$ & $5.9 \pm 1.2$ & $1.1 \pm 0.3$ & $0.5 \pm 0.2$ & $16.7 \pm 4.5$ & $109 \pm 44$ & $13.3 \pm 13.9$ & $87 \pm 39$ \\
\hline \multirow[t]{2}{*}{ MY } & Rice & $20.1 \pm 9.7$ & $5.9 \pm 0.9$ & $1.3 \pm 0.3$ & $0.4 \pm 0.1$ & $11.9 \pm 7.9$ & $105 \pm 40$ & $14.9 \pm 10.6$ & $102 \pm 44$ \\
\hline & Maize & $15.8 \pm 9.0$ & $6.2 \pm 1.2$ & $1.2 \pm 0.6$ & $0.8 \pm 0.4$ & $17.5 \pm 6.7$ & $111 \pm 44$ & $18.0 \pm 17.5$ & $87 \pm 28$ \\
\hline \multirow[t]{2}{*}{$\mathrm{SE}$} & Rice & $25.7 \pm 9.3$ & $6.1 \pm 0.7$ & $1.5 \pm 0.4$ & $0.6 \pm 0.5$ & $19.3 \pm 7.3$ & $137 \pm 37$ & $12.5 \pm 12.2$ & $80 \pm 31$ \\
\hline & Maize & $21.2 \pm 8.9$ & $5.8 \pm 0.9$ & $1.1 \pm 0.4$ & $0.5 \pm 0.2$ & $22.4 \pm 7.9$ & $127 \pm 40$ & $17.5 \pm 15.7$ & $102 \pm 63$ \\
\hline \multirow[t]{2}{*}{$\mathrm{NE}$} & Rice & $22.9 \pm 4.5$ & $6.1 \pm 0.9$ & $1.3 \pm 0.2$ & $0.4 \pm 0$ & $10.0 \pm 7.1$ & $70 \pm 27$ & $13.2 \pm 5.2$ & $110 \pm 17$ \\
\hline & Maize & $23.6 \pm 7.5$ & $6.7 \pm 1.1$ & $1.5 \pm 0.5$ & $0.7 \pm 0.2$ & $15.3 \pm 4.4$ & $122 \pm 49$ & $16.6 \pm 12.1$ & $96 \pm 47$ \\
\hline
\end{tabular}

Being avoided the plot near road and accumulation of fertilizer, the experiment selected plots with flat terrain, uniform and different levels of soil fertility, and the dry land should be chosen from plots with gentle slope, uniform thickness and fertility of no difference or little difference. In all districts and counties, the local soil mainly planted rice and maize have been selected, and each type of soil for each crop have been arranged more than 10 test points with uniform distribution according to the high, middle and low fertility level. The varieties for trials were mainly popularized in this region, and the size of experimental plots was 13 20 square meters, which were designed to be a group featuring consistent soil fertility, protective line between plots and randomized block layout with 2 3 times replication in general.

With nitrogenous fertilizer being urea( $\mathrm{N}$ 46.4\%), phosphatic fertilizer being super-phosphate(P2O5 12\%) and potassic fertilizer being potassium chloride(K2O 60\%), the application of fertilizers were conducted and the fertilizers of phosphate and potash were applied as 
basal dressing; while the nitrogenous fertilizer was used in twice, $50 \%$ as basal fertilizer and other $50 \%$ as tillering fertilizer or panicle fertilizer. The size of testing plots mainly were 20 30 square meters. According to the experimental data, the basic properties of testing soils planted with rice and maize in different regions were calculated and presented in table 2 . The planting methods all were one harvest semilate rice, and varieties of rice and maize were shown in table 4 .

Table 4 The fertilization rate and major cultivars of rice and maize in different regions of Chongqing

\begin{tabular}{|c|c|c|c|c|c|}
\hline \multirow{2}{*}{ Region } & \multirow{2}{*}{ Crop } & \multicolumn{3}{|c|}{ Fertilization rate $(\mathrm{kg} \cdot \mathrm{hm}-2)$} & \multirow{2}{*}{ Major cultiva } \\
\hline & & $\mathrm{N}$ & P2O5 & $\mathrm{K} 2 \mathrm{O}$ & \\
\hline \multirow{2}{*}{ WY } & \multirow{2}{*}{$\begin{array}{l}\text { Rice } \\
\text { Maize }\end{array}$} & $153.0 \pm 15.7$ & $87.0 \pm 12.6$ & $92.0 \pm 20.3$ & xinongy30, weitian9, Q you6, Y liangyou2.wanyou 6 \\
\hline & & $216.4 \pm 24.8$ & $97.6 \pm 31.6$ & $93.2 \pm 17.6$ & dongdan80, qiandan15, haodan10, jinkun9, jingke2000 \\
\hline \multirow{2}{*}{ MY } & \multirow{2}{*}{$\begin{array}{l}\text { Rice } \\
\text { Maize }\end{array}$} & $148.9 \pm 18.1$ & $85.04 \pm 17.3$ & $84.4 \pm 19.4$ & gangyou88, tianfengyou109, gangyou88, gangyou725 \\
\hline & & $211.4 \pm 19.1$ & $90.0 \pm 12.4$ & $88.0 \pm 10.9$ & xindan6, qiandan15, qingyou108, runnong88, \\
\hline \multirow{2}{*}{ SE } & \multirow{2}{*}{$\begin{array}{l}\text { Rice } \\
\text { Maize }\end{array}$} & $150.3 \pm 34.9$ & $85.5 \pm 15.9$ & $85.5 \pm 15.9$ & wanyou6, yuyou20, wugeng13, xianyou559, Q you 6 \\
\hline & & $198.9 \pm 37.2$ & $85.8 \pm 16.2$ & $85.8 \pm 16.2$ & zhengda999, linao1, zhongnong8, jinhai5 \\
\hline \multirow{2}{*}{ NE } & \multirow{2}{*}{$\begin{array}{l}\text { Rice } \\
\text { Maize }\end{array}$} & $150.0 \pm 20.4$ & $85.4 \pm 10.8$ & $83.1 \pm 16.2$ & aiyu1, zhongyou 177 , qinyou88, gangyou88 \\
\hline & & $215.8 \pm 37.8$ & $87.9 \pm 7.6$ & $97.0 \pm 27.3$ & changdan46, aoyu17, changdan 46 , luyu13, wandan 13 \\
\hline \multirow{2}{*}{$\begin{array}{l}\mathrm{CQ} \\
\text { Average }\end{array}$} & \multirow{2}{*}{$\begin{array}{l}\text { Rice } \\
\text { Maize }\end{array}$} & $151.0 \pm 20.4$ & $86.0 \pm 14.4$ & $89.0 \pm 19.7$ & \\
\hline & & $212.0 \pm 30.0$ & $93.0 \pm 24.6$ & $92.0 \pm 18.8$ & \\
\hline
\end{tabular}

Collection and measurement of field test samples

Before rice and maize were planted, the soil samples were taken from the plough layer $(0 \sim 20 \mathrm{~cm})$ at each test sites to measure the basic nutrient index. S method was used to collect soil samples, after air-dried indoor and sieved ( $1 \mathrm{~mm}$ and $0.25 \mathrm{~mm}$ ), the soil basic indexes were measured by methods of potassium dichromate volumetry for organic matters, semi-micro Kjeldahl for total nitrogen, alkaline hydrolysis diffusion for alkali-hydrolyzable nitrogen, Olsen method for available phosphorus, ammonium acetate extraction-flame photometric for rapidly available $\mathrm{K}$ and $\mathrm{pH}$ potentiometric method for $\mathrm{pH}$ (2.5: 1).

At maturity, the output of each plots were recorded, and grain and straw were harvested to determine nutrient content. Respectively, after the grain and straw were dried, ground and sieved, the nutrients of nitrogen, phosphorus and potassium were measured, then after cooking by H2SO4-H2O2 method, other nutrient contents were determined by Kjeldahl method for total nitrogen, Olsen method for total phosphorus and flame photometer for total potassium [9].

Data processing. The inherent soil productivity was evaluated by crop yield without applications of any fertilizer[10], which was shown by rice yield of no-fertilizer(CK) in this study, meanwhile, the contribution rate of soil and fertilizer were calculated in order to evaluate the dependency of crop yield to soil and fertilizer.

$$
\begin{aligned}
& R C_{\text {soil }}(\%)=\frac{Y_{\mathrm{CK}}}{Y_{\mathrm{NPK}}} \times 100 \\
& R C_{\text {fertilizer }}(\%)=\frac{Y_{\mathrm{NPK}} Y_{\mathrm{CK}}}{Y_{\mathrm{NPK}}} \times 100
\end{aligned}
$$

In the formula, YCK was the average output of CK and YNPK was the average output of NPK.

The supply capacity of soil nutrient was an important factor affecting basic soil productivity, and the higher the supply capacity of soil nutrient was, the easier the high basic soil productivity was obtained. The supply capacity of soil nutrient was expressed by nutrient uptake of above-ground part without applying this nutrient, such as the supply capacity of nitrogen, phosphorus and potassium were respectively expressed by uptake of $\mathrm{N}, \mathrm{P}$ and $\mathrm{K}$ with treatments of PK, NK and NP for plants at above-ground part. Meanwhile, the effect of soil nutrient on yield was expressed by Ci (Contribution of nutrient supply to yield), and the calculation method of it for specific nutrient was in terms of percentage of crop yield with the lack of this nutrient to crop yield with the balance of fertilization [11]. The effect of yield increase for different fertilizers was indicated by Ii (increment rate by 
fertilizer) and the calculation method was the percentage of yield without applying this nutrient to the difference of yield with balanced fertilization. The formula was as follows:

Contribution rate of $\mathrm{N}$ in soil:

$$
C_{\mathrm{sN}}(\%)=\frac{Y_{\mathrm{PK}}}{Y_{\mathrm{NPK}}} \times 100
$$

Yield increase rate by $\mathrm{N}$-fertilizer:

$$
I_{\mathrm{fN}}(\%)=\frac{Y_{\mathrm{NPK}} Y_{\mathrm{PK}}}{Y_{\mathrm{PK}}} \times 100
$$

Contribution rate of $\mathrm{P}$ in soil:

$$
C_{\mathrm{sP}}(\%)=\frac{Y_{\mathrm{NK}}}{Y_{\mathrm{NPK}}} \times 100
$$

Yield increase rate by P-fertilizer:

$$
I_{\mathrm{fP}}(\%)=\frac{Y_{\mathrm{NPK}} Y_{\mathrm{NK}}}{Y_{\mathrm{NK}}} \times 100
$$

Contribution rate of $\mathrm{K}$ in soil:

$$
C_{\mathrm{sK}}(\%)=\frac{Y_{\mathrm{NP}}}{Y_{\mathrm{NPK}}} \times 100
$$

Yield increase rate by K-fertilizer

$$
I_{\mathrm{fK}}(\%)=\frac{Y_{\mathrm{NPK}} Y_{\mathrm{NP}}}{Y_{\mathrm{NP}}} \times 100
$$

The SYI (sustainable yield index) of crop yield was a parameter of measuring whether the system could continuously produce, and the greater the SYI was, the better the sustainability of production was. The stability of crop yield was measured by SI (Stability index), and the lower the SI was, the more stable the yield was [12]. The calculation method was as follows:

$$
\begin{aligned}
& \text { Sustainability index: } \quad Y_{\mathrm{NPK}} \max \\
& \text { Stability index: }
\end{aligned}
$$$$
S Y I=\frac{\bar{Y}_{\mathrm{NPK}} \sigma}{Y_{\mathrm{NPK} \max }}
$$

In the formula, $\bar{Y}$ NPK was the average output, $\sigma$ was the standard deviation, YNPK-max was the highest output in test, and STD (YNPK) was the standard deviation of NPK.

In order to evaluate the response of yield and fertilizer of rice and maize to basic soil productivity, using the method of average per unit area yield[13] in this article, according to the compared yield with treatment of no-fertilizer, the soil productivity of 433 rice trials have been divided into five grades of $<4,4 \sim 5,5 \sim 6,6 \sim 7$ and $>7 \mathrm{t} \cdot \mathrm{hm}-2$ and the sample size of each grade was $28,63,137,118$ and 87. Using the same way, 270 maize trials were divided into 5 grades of $<3,3-4,4-5,5-6$ and 6 t.hm-2.

To compare the fertilizer effect, sustainability and stability of yield in different fertility levels of plots, through grade of soil productivity. Data processing and statistical analysis were carried out in software of Microsoft Excel 2017 and SigmaPlot 2.0. 


\section{Result analysis}

\section{Contribution rate of soil productivity of different farmland types in Chongqing}

Table 5 Paddy soil productivity and contribution rate of soil productivity and fertilizer to yield in Chongqing

\begin{tabular}{|c|c|c|c|c|c|}
\hline \multirow{2}{*}{ Region } & \multicolumn{3}{|c|}{ Yield $(\mathrm{t} \cdot \mathrm{hm}-2)$} & \multicolumn{2}{|l|}{ Contribution rate(\%) } \\
\hline & Yield-CK & Yield-NPK & Increased yield & Contribution of soil productivity & Contribution of fertilizer \\
\hline wY & $6.2 \pm 1.3$ & $8.6 \pm 1.2$ & 2.4 & 72 & 28 \\
\hline MY & $5.8 \pm 1.3$ & $8.3 \pm 1.2$ & 2.5 & 70 & 30 \\
\hline $\mathrm{SE}$ & $5.4 \pm 0.9$ & $7.5 \pm 1.2$ & 2.1 & 72 & 28 \\
\hline $\mathrm{NE}$ & $5.7 \pm 1.4$ & $7.5 \pm 1.5$ & 1.8 & 76 & 24 \\
\hline Average & $6.0 \pm 1.3$ & $8.3 \pm 1.3$ & 2.3 & 72 & 28 \\
\hline
\end{tabular}

(Basic Soil Productivity, BSP) referred to the soil production capacity when there were no water and fertilizer input of dry land and no nutrient input of paddy field in test season, under the circumstances of site conditions, physical and chemical properties of soil profile and level of agricultural infrastructure construction, after years of cultivation with water and fertilizer [14]. Most of the studies use CK yield of long-term-no-fertilizer to indicate BSP, while some experts use the crop yield of no nitrogen fertilizer [15], but its representation was less than the former, so this article was still using the former.

As shown in table 5, the basic soil productivity of paddy field of Chongqing was $6.0 \mathrm{t} \mathrm{hm}-2$, but there was a significant difference of the regions, that the highest was $6.2 \mathrm{t} \mathrm{hm}-2$ in western area, followed by $5.8 \mathrm{t} \mathrm{hm-2} \mathrm{in} \mathrm{MY} \mathrm{area} \mathrm{and} \mathrm{the} \mathrm{lower} \mathrm{in} \mathrm{SE} \mathrm{and} \mathrm{NE} \mathrm{were} 5.4 \mathrm{t} \mathrm{hm}-2$ and $5.7 \mathrm{t} \mathrm{hm}-2$. In terms of fertilization production, it showed two regional polarization between the area of WY and MY and the other area of SE and NE, of which the basic soil productivity in WY and MY were 8.6t $\mathrm{hm}-2$ and $8.3 \mathrm{thm}-2$, both significantly higher than the fertilization production of $7.5 \mathrm{t} \mathrm{hm}-2$ in SE and NE. In terms of yield increase by fertilization, the average in CQ was $2.3 \mathrm{t} \mathrm{hm}-2$, and the regional differences of it was similar to fertilization production, higher in WY and MY, respectively being 2.4 $\mathrm{t} \mathrm{hm}-2$ and $2.5 \mathrm{t} \mathrm{hm}-2$, that showed there was still a large increase space in this region, while the lower of SE and NE were $1.8 \mathrm{thm}-2$ and $2.3 \mathrm{t} \mathrm{hm}-2$. The contribution rate of soil fertility and contribution rate of fertilizer in different regions of Chongqing was relatively small, which were respectively between $70 \%-76 \%$ and $24 \%-30 \%$, with the average of $72 \%$ and $28 \%$ in the CQ. The contribution rate of soil fertility was close to $66.3-78.4 \%$ of paddy soil in Xianyou city of Fujian, higher than 60.3\% of early season rice and $40.1 \%$ of late rice in yellow sand field. Lu Yanhong and others [15] used long-term positioning tests also to show that the dependence of rice yield on fertilizer could be reduced by increasing basic soil productivity, so that the amount of fertilizer could be reduced appropriately. From the view of different regions, the dependence of yield on basic soil productivity in NE of Chongqing was higher than that in other areas, while the dependence on fertilizer in MY region was the highest.

Table 6 Dry land soil productivity and contribution rate of soil productivity and fertilizer to yield in Chongqing

\begin{tabular}{|c|c|c|c|c|c|}
\hline \multirow{2}{*}{ Region } & \multicolumn{3}{|c|}{ Yield $(\mathrm{t} \cdot \mathrm{hm}-2)$} & \multicolumn{2}{|l|}{ Contribution rate(\%) } \\
\hline & Yield-CK & Yield-NPK & Increased yield & Contribution of soil productivity & Contribution of fertilizer \\
\hline WY & $4.0 \pm 1.0$ & $7.0 \pm 1.7$ & 3.0 & 59 & 41 \\
\hline MY & $3.7 \pm 1.5$ & $7.0 \pm 1.8$ & 3.2 & 53 & 47 \\
\hline SE & $3.9 \pm 1.5$ & $6.9 \pm 1.5$ & 3.0 & 57 & 43 \\
\hline $\mathrm{NE}$ & $4.2 \pm 1.3$ & $7.4 \pm 1.7$ & 3.2 & 57 & 43 \\
\hline Average & $4.0 \pm 1.3$ & $7.1 \pm 1.7$ & 3.1 & 57 & 43 \\
\hline
\end{tabular}

According to the test results of 270 fields, the average basic soil productivity of maize in Chongqing was $48 \mathrm{thm}-2$, but the regional difference was relatively small, with the highest in NE, the 
lowest in MY, and the difference was $0.58 \mathrm{t} \mathrm{hm}-2$, while the WY and SE were $3.9 \mathrm{t} \mathrm{hm}-2$ and $4.0 \mathrm{t}$ $\mathrm{hm}-2$. From the term of fertilization production, the highest was $7.4 \mathrm{t} \mathrm{hm}-2$ of NE area, the other three areas had little difference between 6.9-7.0 t hm-2, and the average of the CQ was $7.1 \mathrm{t} \mathrm{hm}-2$. The yield increase by fertilization in various ecological regions also had few differences, and the higher

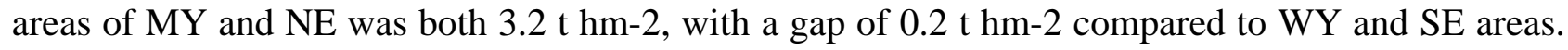
This type of difference was also reflected in contribution rate of soil productivity and contribution of fertilizer, and the gap of contribution rate of soil productivity between the highest area of WY and the lowest area of MY was 6\%. While the SE and NE were both 57\%, and the average in the CQ was 57\% which was lower than the results studied by Cha Yan on spring maize in black soil region of the NE, with a average of basic soil productivity of spring maize in black soil area between $74.4-84.7 \%$ under the condition of long-term fertilization, also lower than that of the North China Plain of 51\%, but higher than the region in central and southern China of 33\%. The average contribution of fertilizer in the CQ was 43\%, which indicated that the maize yield in dry land had very high dependence on fertilizer.
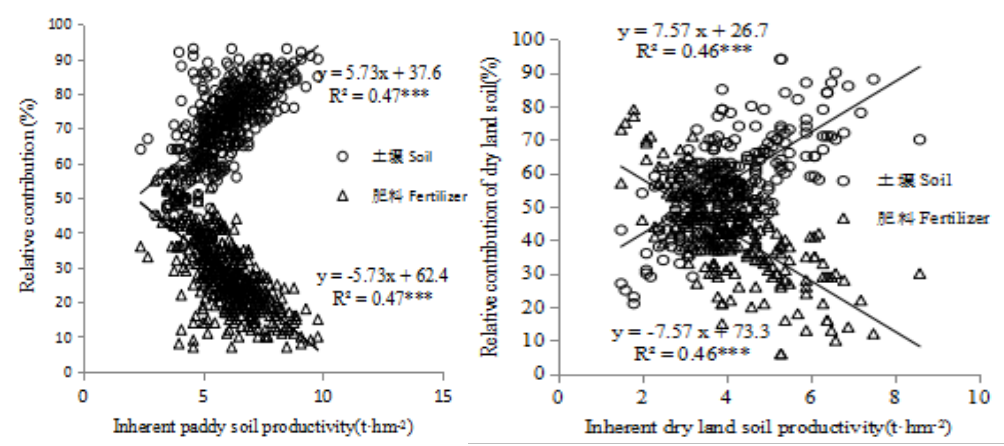

Fig 2 The relative contribution of inherent paddy and dry soil productivity and NPK fertilization to grain yield of rice grown.

In both paddy and dry land, the basic soil productivity and relative contribution rate were significantly positively correlated, while the relative contribution rate of fertilizer was significantly negatively correlated with basic soil productivity. This showed that the higher the basic soil productivity was, the greater the contribution to yield of soil nutrients were, and the lower the basic soil productivity was, the greater the contribution of fertilizer was, coming to a similar conclusion in the Sichuan Basin studied by Liang Tao and in the black soil region of Northeast China studied by Cha Yan $[18,19]$.

The effect of soil nutrient supply capacity on crop yield in different cultivated land types

Table 7 Nutrient supply capacity of paddy soils and yield increment rate by fertilizer in Chongqing

\begin{tabular}{cllllll}
\hline & \multicolumn{3}{c}{ Nutrient supply capacity (kg.hm-2) } & \multicolumn{5}{c}{ Yield increment rate by fertilizer (\%) } \\
\cline { 2 - 7 } & $\mathrm{N}$ & $\mathrm{P}$ & $\mathrm{K}$ & $\mathrm{N}$ & $\mathrm{P}$ & $\mathrm{K}$ \\
\hline SY & $120 \pm 27$ & $58 \pm 17$ & $187 \pm 61$ & 25.3 & 13.4 & 9.6 \\
MY & $91 \pm 23$ & $60 \pm 17$ & $157 \pm 53$ & 33.3 & 13.8 & 11.2 \\
SE & $84 \pm 28$ & $52 \pm 18$ & $142 \pm 53$ & 27.0 & 12.9 & 10.3 \\
NE & $123 \pm 19$ & $54 \pm 11$ & $185 \pm 13$ & 28.0 & 10.2 & 7.2 \\
Mean & $101 \pm 30$ & $57 \pm 17$ & $165 \pm 58$ & 27.9 & 13.3 & 9.9 \\
\hline
\end{tabular}

In Chongqing, the supply capacity of paddy soil of nitrogen, phosphorus and potassium were 101, 57 and $165 \mathrm{~kg} \mathrm{hm}-2$, and the yield increase by fertilizer of nitrogen, phosphorus and potassium were $27.9 \%, 13.3 \%$ and $9.9 \%$, while the nitrogen fertilizer was still a key factor to ensure yield increase, and the yield increase by fertilizer of nitrogen, phosphorus and potassium in Sichuan Basin were $26.6 \%, 14.4 \%$ and $10.3 \%$ [18], approaching to the results of this study. The supply capacity of soil nutrient in different ecological regions had significant difference, and the higher the basic soil productivity was, the stronger the supply capacity of soil nutrient of nitrogen, phosphorus and potassium was [20]. According to table 7, the supply capacity of paddy soil of nitrogen, phosphorus and potassium in WY were both high, and the supply capacity of these three kinds of nutrient 
elements in SE was relatively low. The yield increase by fertilizer in different regions were also different, and the yield increase by fertilizer of phosphorus and potassium in NE region was lower than that of other regions, as this might be related to the low temperature in the region affecting the effectiveness of phosphorus and potassium fertilizers, while the yield increase by fertilizer of nitrogen in WY was lower than that of the other three areas, indicating that the effect of nitrogen fertilizer in the region was not as good as other regions.

Table 8 Nutrient supply capacity of dry land soils and yield increment rate by fertilizer in Chongqing

\begin{tabular}{cllllll}
\hline & \multicolumn{5}{c}{ Nutrient supply capacity $(\mathrm{kg} \cdot \mathrm{hm}-2)$} & \multicolumn{4}{l}{ Yield increment rate by fertilizer $(\%)$} \\
\cline { 2 - 6 } Region & $\mathrm{N}$ & $\mathrm{P}$ & $\mathrm{K}$ & $\mathrm{N}$ & $\mathrm{P}$ & $\mathrm{K}$ \\
\hline SY & $112 \pm 36$ & $46 \pm 12$ & $118 \pm 43$ & 30.8 & 20.7 & 12.8 \\
MY & $90 \pm 32$ & $49 \pm 20$ & $108 \pm 53$ & 33.7 & 20.6 & 11.1 \\
SE & $103 \pm 58$ & $47 \pm 20$ & $81 \pm 54$ & 26.1 & 17 & 13 \\
NE & $86 \pm 24$ & $52 \pm \pm 25$ & 33.5 & 16.3 & 10.1 \\
Mean & $102 \pm 43$ & $47 \pm 18$ & $101 \pm 50$ & 30.7 & 19.2 & 12.1
\end{tabular}

In Chongqing, the supply capacity of dry land soil of nitrogen, phosphorus and potassium were 102, 47, $101 \mathrm{~kg} \mathrm{hm}-2$, the yield increase by fertilizers of nitrogen, phosphorus and potassium were $30.7 \%, 19.2 \%$ and $12.1 \%$, indicating that the yield increase still needed strong support of nitrogen. In different ecological regions, the highest supply capacity of soil nutrient of nitrogen and potassium were 112 and $118 \mathrm{~kg} \mathrm{hm-2} \mathrm{in} \mathrm{WY} \mathrm{area,} \mathrm{while} \mathrm{the} \mathrm{supply} \mathrm{capacity} \mathrm{of} \mathrm{dry} \mathrm{land} \mathrm{soil} \mathrm{of} \mathrm{nitrogen} \mathrm{and}$ potassium was relatively low in NE area, and the supply capacity of soil phosphorus was in 46-52 kg $\mathrm{hm}-2$, with an average of $47 \mathrm{~kg} \mathrm{hm}-2$. From the term of yield increase by fertilizer, phosphorus and potassium in SE area still showed a lower rate, and the utilization rate of phosphorus and potassium in WY area was relatively high.
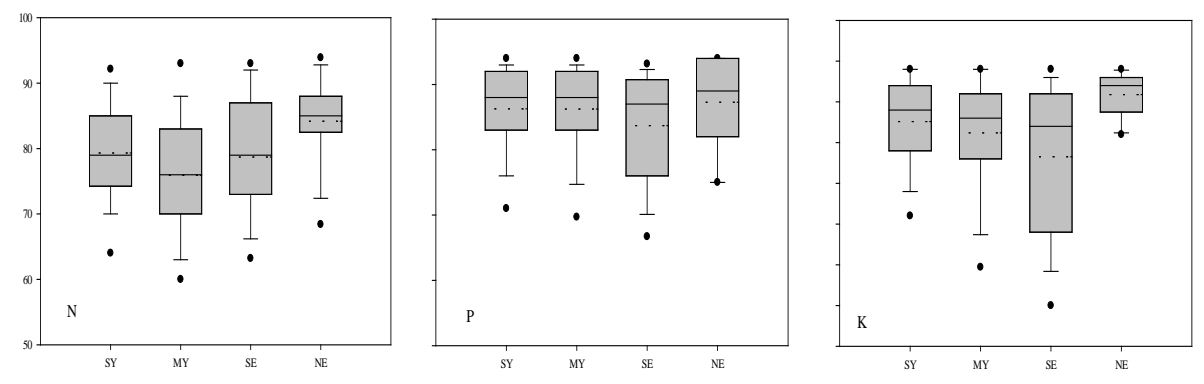

Fig. 3 Contribution of inherent paddy soil nutrient supply (IDNS) to rice yield (NPK treatment).

Solid and dashed lines in this figure indicate median and mean value, respectively. The box boundaries indicate upper and lower quartiles, the whisker caps indicate 90th and 10th percentiles, and the circles indicate the 95th and 5th percentiles. The box-plot is the same as blow.

According to Figure 3, the contribution on yield of soil base nutrient type in different paddy was different, and the contribution on yield of soil essential nutrients of phosphorus and potassium were higher than that of nitrogen, while soil phosphorus was slightly higher than potassium, and the contribution on yield of soil phosphorus in different ecological areas was relatively consistent, with the difference less than nitrogen and potassium. This might be related to delayed phosphate fertilizer, that was to say the phosphate fertilizer applied in the soil for many years had a fixed accumulation, and the stable effect after delays were also gradually appearing and eventually contribute to crop production, while the dependence on fertilizer of nitrogen and potassium was higher. According to the distribution of contribution of nutrients in different ecological regions, the distribution between upper and lower quartiles of contribution of paddy soil nutrients of nitrogen, phosphorus and potassium in SE were wider, indicating that the difference of paddy soil in the area was higher than other regions, with a narrower distribution in NE area due to its small area of paddy field and relative concentrated distribution. 
Solid and dashed lines in this figure indicate median and mean value, respectively. The box boundaries indicate upper and lower quartiles, the whisker caps indicate 90th and 10th percentiles, and the circles indicate the 95th and 5th percentiles. The box-plot is the same as blow.
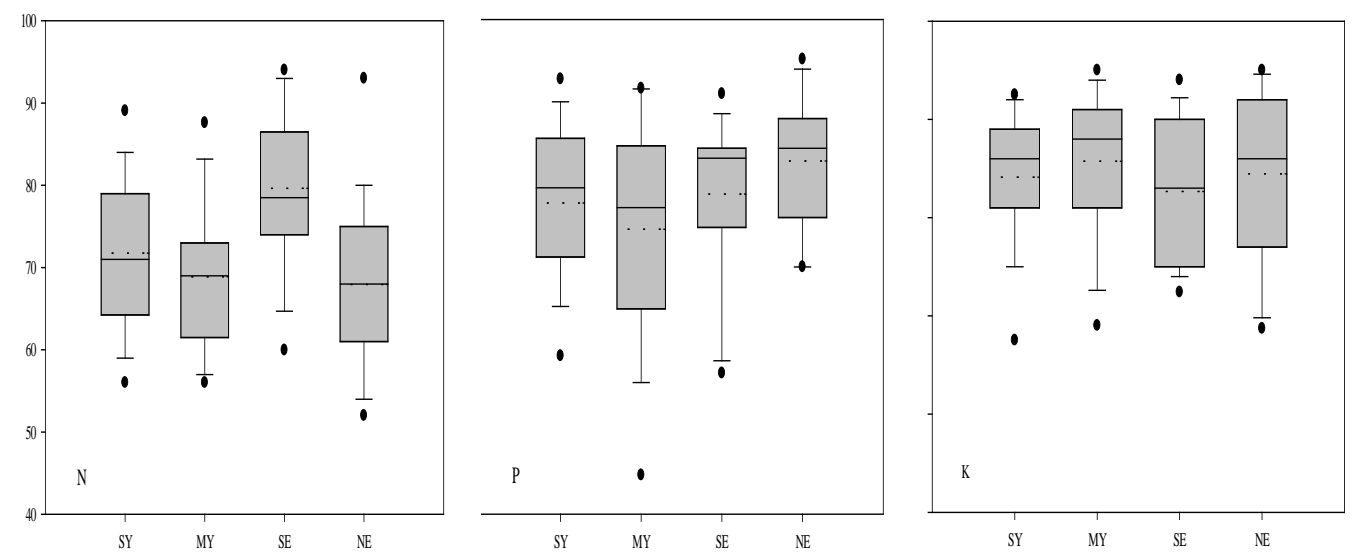

Fig. 4 Contribution of inherent dry land soil nutrient supply (IDNS) to maize yield (NPK treatment).

Influence of fertilization effects and soil basic productivity over soil yield. According to Figure 3 3, the contribution on yield of dry land soil nutrients of phosphorus and potassium were also higher than soil nitrogen, and the average contribution rate of soil nutrients of phosphorus and potassium in each regions were lower than the median, while soil nitrogen was slightly higher than or close to the median, this showed that compared with nitrogen, the distribution of contribution rate of soil nutrients of phosphorus and potassium in each regions were more nonuniform, concentrated above the average, and the soil of low contribution rate had a farther deviation.
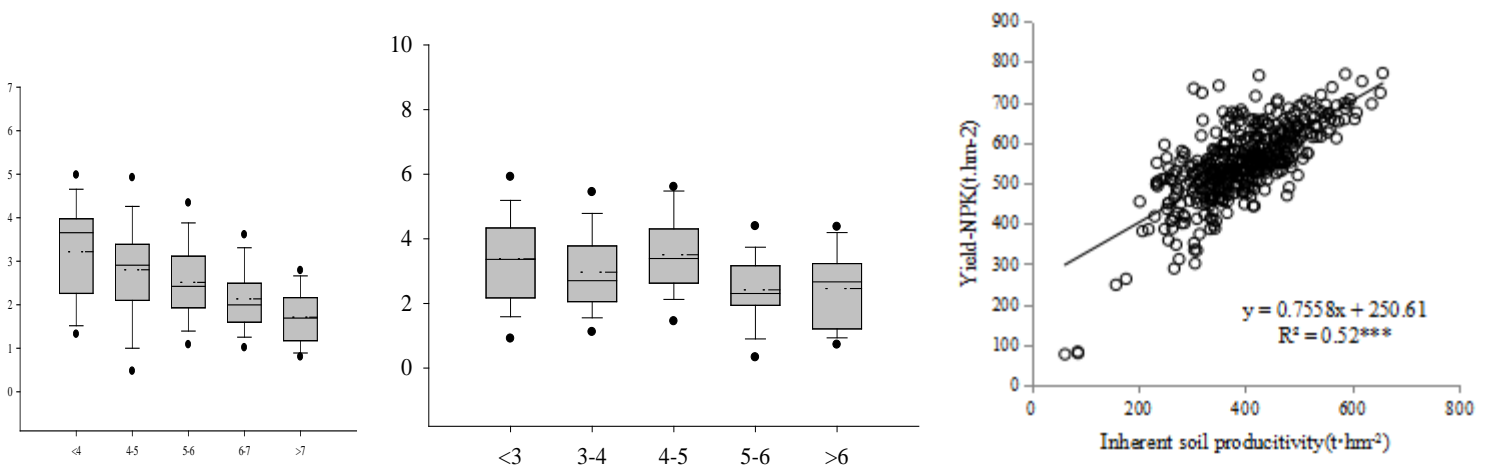

Fig.5 The relationship between inherent soil productivity (yield-CK) and optimal yield (yield-NPK) (A), and between classification of ISP and increment of grain yield by fertilization (B)

From Figure 5, there was a significant positive correlation between paddy soil productivity and fertilization production, along with the increase of paddy soil productivity, the fertilization production increased continuously. There was also a certain relationship between basic soil productivity and yield increase by fertilizer, as shown in figure, paddy soil productivity have been divided into five grades of $<4,4-5,5 \sim 6,6 \sim 7$ and $>7$, following the increase of paddy soil productivity, the fertilization production was on the decline constantly, when basic soil productivity was $<4 \mathrm{thm}-2$, the yield increase by fertilizer could reach to $3.2 \mathrm{t} \mathrm{hm}-2$, while basic soil productivity rose to $>7 \mathrm{t}$ $\mathrm{hm}-2$, the yield increase by fertilizer decreased to $1.7 \mathrm{t} \mathrm{hm}-2$, indicating the low basic soil productivity had a higher potential of yield increase. 


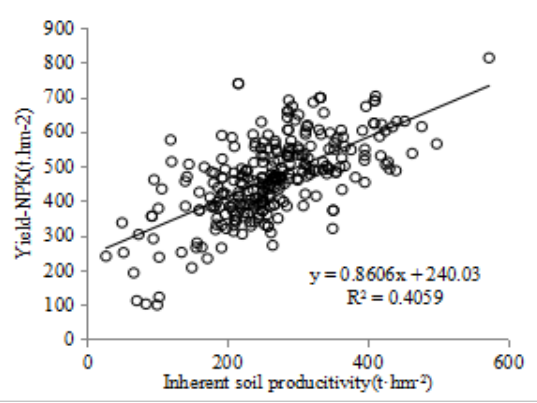

Fig.6 The relationship between inherent soil productivity (yield-CK) and optimal yield (yield-NPK) (A), and between classification of ISP and increment of grain yield by fertilization (B)

Statistics showed that the correlation between dry land basic productivity and fertilization production was significant, and the fertilization production of maize in dry land increased with the increase of basic soil productivity. From the figure, the dry land basic productivity have been divided into five grades of $<3,3-4,4-5,5-6$ and $>6$, and it can be seen that there was no significant negative correlation between dry land basic productivity and yield increase by fertilizer, but the yield increase of low levels $(5-6,>6)$ was higher than high level $(<3,3-4,4-5)$, with the lowest of yield increase by fertilizer of medium level(4-5), indicating that the soil of this level had higher potential of yield increase by fertilizer. The difference of basic soil productivity was mainly due to the increase of organic matter content in soil [10]. In the past 20 years, the improvement of organic matter in cultivated land was mainly attributed to straw returning to field, the popularization and application of organic fertilizer, the application of synthetic fertilizers, and measures of no-tillage and minimum tillage [21], and long term returning straw to field could improve the content of organic matter and total nitrogen more than $10 \%$ [22].

Relationship between basic soil productivity and stability and sustainability of yield in paddy fields. According to the order from low to high, the basic soil productivity of rice have been divided into five grades $(<4,4 \sim 5,5 \sim 6,6 \sim 7,>7)$, calculating sustainability index and stability index for each level, forming figure $3 \sim 9$, and it can be seen from the figure, the stability and sustainability of yield in paddy field increased with level of soil productivity, when the basic soil productivity of paddy was between the low level (grade 2) and the high level (grade 5), the sustainable index of yield rises from $54 \%$ to $75 \%$, and the stability index decreases from $18.3 \%$ to $9.2 \%$. The lowest level (grade 1) did not conform to this rule, indicating that rice may increase its stability and sustainability after the yield below certain level.
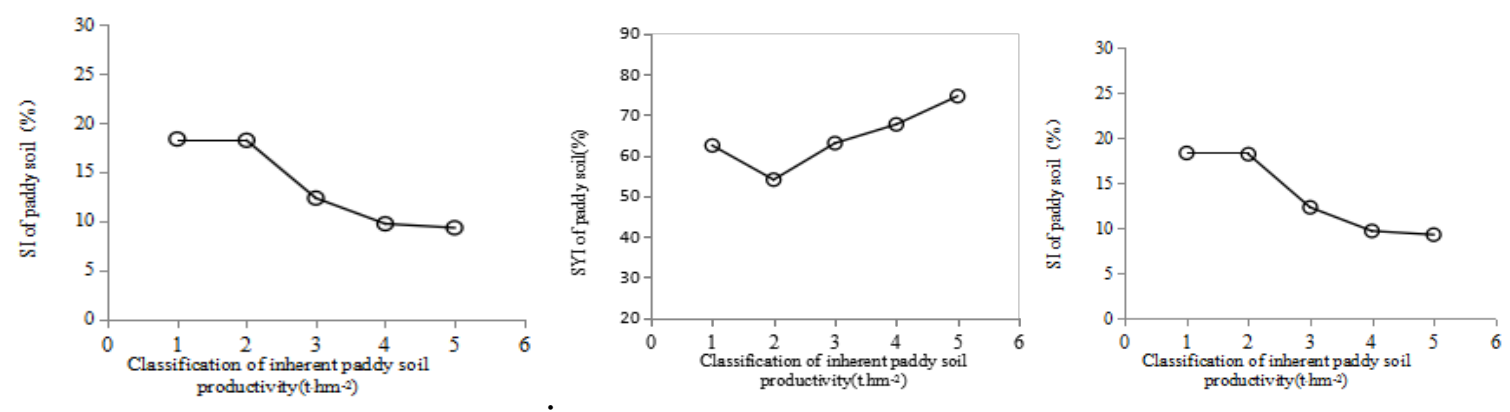

Fig.7 Effect of inherent paddy soil productivity (CK) on stability index (SI) (A) and Effect of sustainable yield index (SYI) of rice yield (NPK) (B).

According to the order from low to high, the basic soil productivity of rice have been be divided into five grades $(<3,3 \sim 4,4 \sim 5,5 \sim 6,>6)$. As shown in figure 7 , from low to high level of basic soil productivity, the sustainability and stability of yield were improved, while in figure 3 8A, with the level increases, the sustainability index increased from $46 \%$ to $65 \%$, and the stability index decreased from $27 \%$ to $14 \%$. It was worth mentioning that whether it was sustainability index and stability index, there was a mutation process between the low levels (grade 1 and grade $2,<4 \mathrm{thm}$-2) and high grades (grade 3 5, $>4 \mathrm{t} \mathrm{hm}-2$ ), and the stability and sustainability of the former was significantly 
lower than the latter, showing that the stability and sustainability of dry land with basic soil productivity of $>4 \mathrm{t} \mathrm{hm-2}$ were higher.

\section{Discussion}

It can be seen from the 433 trials of rice and 270 trials of maize, there was a significant positive correlation between fertilization production and basic soil productivity, and this showed that both paddy and dry land, the basic soil productivity played an important role in land productivity which have also been proved by previous studies[21]. There also was a very close relationship between the basic soil productivity and fertilization, that long-term combined application of NPK fertilizer or long-term combined application of NPK fertilizer and straw were beneficial to maintenance or improvement of contribution rate of basic soil productivity, while long-term no-fertilizer will lead to reduce contribution rate of basic soil productivity [17], and the result was the same as the studies by Liao Yulin related to 66 rice harvests of long-term different fertilization test for 33 consecutive years. The soil with high basic soil productivity had great potential for high yield, and the soil with low basic soil productivity could only achieve corresponding high yield by increasing the amount of fertilizer . In the aspect of yield increase by fertilization, this study showed that the application of fertilizers of nitrogen, phosphorus and potassium could increase the rice yield by $27.9 \%, 13.3 \%$ and 9.9\% respectively, and the yield increase rate of maize with application of three kinds of fertilizer were $30.7 \%, 19.2 \%$ and $12.1 \%$. Yu Wantai . The application of fertilizers of nitrogen, phosphorus and potassium could apparently increase crop yield through the studies of long-term located fertilization, and the yield increase rate were $32.1 \%, 15 \%$ and $10.9 \%$, while the results studied by Liang Tao and others in Sichuan Basin were 26.6\%, 14.4\% and 10.3\%. In this study, it was found that there was a significant positive correlation between basic soil productivity and fertilization production of paddy field and dry land, along with the increase of basal soil productivity, the fertilization production increased constantly. Moreover, the basic soil productivity also had some relationship with the yield increase by fertilization, along with the increase of level of paddy basic soil productivity, the yield increase by fertilization was also declining continuously. This results were the same with the studies by Zhang Xiangming and other that the higher the basic soil productivity of paddy was, the easier the high yield obtained, but the range of yield increase by fertilization became lower and lower. The results of Lu Yanhong's research were the same. Therefore, by improving the basic soil productivity of paddy fields, not only could the productive potential of farmland be excavated and the yield be increased, but also the amount of fertilizer could be controlled in the proper range to reduce the pollution of agricultural environment [17].

High and stable yield were the two important goals of the pursuit of our country agriculture, this study showed that the stability and sustainability of rice would be increased continuously after its yield was below a certain level, but high levels of soil productivity also could be maintained stable in high levels of yield, as reflected by constant decline of the stability index along with the increase of the level of soil productivity. Therefore, improving basic soil productivity was not only an effective measure to achieve high yield of soil and reduce dependence on fertilizer, but also the development trend of all sustainable agriculture to meet the grain demand in China in the future.

\section{Conclusions}

(1) There was a significant positive correlation between basic soil productivity and relative contribution rate, and the relative contribution rate of fertilizer was significantly negatively correlated with basic soil productivity. This showed that the higher the basic soil productivity was, the greater the contribution rate on the yield of soil nutrients were, and the lower the basic soil productivity was, the greater the contribution rate on the yield of fertilizers were, while the dependence on fertilizers of maize yield in dry land was higher than that of rice in paddy field. 
(2) There was a significant positive correlation between the basic soil productivity and fertilization production of paddy field and dry land, and the fertilization production also increased along with the increase of basic soil productivity of paddy field.

(3) The higher level of basic soil productivity had higher sustainability and stability, while the stability and sustainability of paddy field was higher than that of dry land.

\section{References}

[1] JIANG Duan-sheng,ZENG Xi-bai,Gao Ju-sheng and Li Liang-fang.Changes of Organic Matter,N,P and K Content of Soil Areas Under Long-term Experment.Agriculutral Sciences in China 2008.7(7):853-859.

[2] TANG Yong-hua, HUANG Yao. Spatial Distribution Characteristics of the Percentage of Soil Fertility Contribution and Its Associated Basic Crop Yield in Mainland China. 2009, 28(5): 1070-1078。

[3] Xi Zhenbang,Lin Bao,Li Jiangkang.The Theory of Present Crop Fertilizer Standard Formulation and Implementation in China.Soil and Fertilizer Sciences in China,1991,3:2-6.

[4] Wang Shanna.Evolution Characteristics of Reddish Paddy Soil Fertility under Long-Term Fertilization and Its Sustainable Utilization in Southern China。Chinese academy of agricultural sciences, 2012,Doctoral thesis.

[5] Yan Yifan, Liu Jianli, Zhang Jiabao. Evaluation method and model analysis for productivity of cultivated land. Transactions of the Chinese Society of Agricultural Engineering (Transactions of the CSAE), 2014, 30(5): 204-210.

[6] Kunzová E, Hejcman M. 2010. Yield development of winter wheat over 50 years of nitrogen, phosphorus and potassium application on Greyic Phaeozem in the Czech Republic. European Journal of Agronomy, 33, 166-174.

[7]LI Jian-jun,XU Ming-gang,XIN Jing-shu,DUAN Jian-jun,REN Yi,LI Dong-chu, HUANG Jing, SHEN Hua-ping, ZHANG Hui-min. Spatial and Temporal Characteristics of Basic Soil Productivity in China. Scientia Agricultura Sinica. 2016,49(8):1510-1519.

[8]Lu Yanhong,Liao Yulin,Zhou Xing,Nie Jun,Xie Jian, Yang Zengping. EFFECT OF LONG-TERM FERTILIZATION ON RICE YIELD AND BASIC SOIL PRODUCTIVITY IN RED PADDY SOIL UNDER DOUBLE-RICE SYSTEM.2015,52(3): 597-605.

[9] Bao S D. Soil and Agricultural Chemistry Analysis. 3rd ed. Beijing: China Agriculture Press, 2007.

[10] Fan M S, Lal R, Cao J, Qiao L, Su Y S, Jiang R F, Zhang F S. Plant-based assessment of inherent soil productivity and contributions to China's cere crop yield increase since 1980. Plos One, 2013, 09, 8(9): 1-11.

[11] Wang D Y, Shi X J, Mao Z Y. Study on nutrient supplying capacity of purple soil under long-term rice-wheat rotation. Journal of Plant Nutrition and Fertilizer Science, 2004, 10(2): 120-126.

[12] Pan G X, Smith P, Pan W N. The role of soil organic matter in maintaining the productivity and yield stability of cereals in China. Agriculture Ecosystems and Environment, 2009, 129: 344-348.

[13] Zeng X M, Han B J, Xu F S, et al. Effect of optimized fertilization on grain yield of rice and nitrogen use efficiency in paddy fields with different basic soil fertilities [J]. Scientia Agricultura Sinica, 2012, 45(14): 2886 - 2894. 
[14] ZHA Yan, WU Xue-ping, HE Xin-hua, ZHANG Hui-min, GONG Fu-fei, CAI Dian-xiong, ZHU Ping and GAO Hong-jun. Basic Soil Productivity of Spring Maize in Black Soil Under Long-Term Fertilization Based on DSSAT Model. Journal of Integrative Agriculture, 2014, 13(2):577-587.

[15] Wang W, Chen W C, Wang K R, Xie X L, Yin C M, Chen A L. 2011. Effects of long-term fertilization on the distribution of carbon, nitrogen and phosphorus in waterstable aggregates in paddy soil. Journal of Integrative Agriculture, 10, 1932-1940.

[16] Zhu Huaming, Wang Meiqin, Wu Zhangmei. Study on the Effect of Fertilization on Red Soil Organic Matter and Soil Nutrient Evolution and Crop Yield. Chinese Journal of Soil Science, 1995, 26 (2) : 76-77.

[17] Lu Y H, Liao Y L, Zhou X, Nie J, Xie J, Yang Z P. Effect of long-term fertilization on rice yield and basic soil productivity in red paddy soil under double-rice system. Acta Pedologica Sinica, 2015, 52(3): 597-605.

[18] LIANG Tao, CHEN Xuan-jing, ZHAO Ya-nan, HUANG Xing-cheng, LI Hong, SHI Xiao-jun, ZHANG Yue-qiang.Response of Rice Yield to Inherent Soil Productivity of Paddies and Fertilization in Sichuan Basin. Scientia Agricultura Sinica, 2015,48(23): 0578-1752

[19] ZHA Yan, WU Xue-ping, HE Xin-hua, ZHANG Hui-min, GONG Fu-fei, CAI Dian-xiong, ZHU Ping and GAO Hong-jun. Basic Soil Productivity of Spring Maize in Black Soil Under Long-Term Fertilization Based on DSSAT Model. Journal of Integrative Agriculture, 2014, 13(2):577-587.

[20] LIAO Yu-lin, LU Yan-hong. NIE Jun. XIE Jian. ZHOU Xing. YANG Zeng-ping. Effects of long-term fertilization on basic soil productivity and nutrient use efficiency in paddy soils. Journal of Plant Nutrition and Fertilizer. 2016, 22(5): 1249 - 1258.

[21] Huang Y, Sun W J. Changes in topsoil organic carbon of croplands in mainland China over the last two decades. Chinese Science Bulletin, 2006, 51(15): 1785-1803.

[22] Wang J Z, Wang X J, Xu M G, Feng G, Zhang W J, Lu C A. Crop yield and soil organic matter after long-term straw return to soil in China. Nutrient Cycling in Agroecosystems, 2015(102): 371-381. 